\title{
The properties and deposition process of GaN films grown by reactive sputtering at low temperatures
}

\author{
E. C. Knox-Davies, J. M. Shannon, and S. R. P. Silva ${ }^{\text {a) }}$ \\ Advanced Technology Institute, University of Surrey, Guildford, Surrey GU2 7XH, United Kingdom
}

(Received 8 August 2005; accepted 17 February 2006; published online 3 April 2006)

\begin{abstract}
Polycrystalline gallium nitride films, $100 \mathrm{~nm}$ to $1 \mu \mathrm{m}$ thick, were deposited under a range of conditions. Substrate electrode temperatures during sputtering were varied from room temperature to $450{ }^{\circ} \mathrm{C}$, the pressure from 0.15 to $6.0 \mathrm{~Pa}$, the nitrogen fraction of the deposition atmosphere from $10 \%$ to $100 \%$ and the target bias from -400 to $-1800 \mathrm{~V}$. The deposition rates as functions of these conditions are in the range $0.5-25 \mathrm{~nm} / \mathrm{min}$. The growth rate is considered to be controlled respectively by the thermally activated desorption from the substrate, changes in the mean free path and concentration of gas particles, differences between the sputter yields of $\mathrm{Ga}$ and $\mathrm{GaN}$ in $\mathrm{Ar}$ and $\mathrm{N}_{2}$, and changes in the ion current and sputter yields. The films are generally columnar, with the grain size increasing with film thickness. The most crystalline films were grown at mid range temperatures, low $\mathrm{N}_{2}$ concentrations, and low target biases, and the most disordered were grown at low pressures. The latter two cases suggest that decreasing the energy of particles incident on the film during deposition results in a more ordered film. The biaxial stress is compressive and shows an increasing trend with the target bias and $\mathrm{N}_{2}$ concentration, reaching $4.7 \mathrm{GPa}$ at $75 \% \mathrm{~N}_{2}$. Oxygen contamination of 3-30 at. \% has a major effect on the optical properties of the films, increasing the band gap values from 3.02 to $>4.0 \mathrm{eV}$ and the Urbach tail energies from around 150 to $840 \mathrm{meV}$ and decreasing the refractive index from 2.46 to 2.03 . At a $40 \% \mathrm{~N}_{2}$ deposition fraction, the $\mathrm{N}: \mathrm{Ga}$ ratio is more or less constant at $1: 1$. Since the absolute oxygen incorporation rate changes very little, it is the relative film deposition rate which determines the final oxygen concentration. Excess Ga at low $\mathrm{N}_{2}$ concentrations causes a decrease in the band gap and an increase in the Urbach tail energy. (C) 2006 American Institute of Physics. [DOI: 10.1063/1.2186380]
\end{abstract}

\section{INTRODUCTION}

In recent years, crystalline GaN and related semiconductors have received much attention for short-wavelength optoelectronic devices and have also found use in a number of other applications. Most materials are epitaxially grown on a variety of substrates, typically sapphire or $\mathrm{SiC},{ }^{1}$ and at high temperatures. This is done by a variety of techniques, including chemical-vapor deposition (CVD), molecular beam epitaxy (MBE), and vapor-phase epitaxy (VPE). Although rf sputtering is comparatively inexpensive, there have been few reports of epitaxially grown, single crystal $\mathrm{GaN}$ using this method. ${ }^{2,3}$ This technique has much more often been used to grow polycrystalline and amorphous materials. ${ }^{4-11}$ These films, using $\mathrm{N}_{2}$ as the reactive gas and $\mathrm{Ar}$ or $\mathrm{N}_{2}$ to sputter a $\mathrm{Ga}$ target, are usually grown at low temperatures $\left(\$ 450{ }^{\circ} \mathrm{C}\right)$. A disordered material grown at low temperatures using remote-plasma CVD has been shown to have potential for lighting and photodiode applications. ${ }^{12,13}$

However, these studies only investigate the effect of changing one and sometimes two of the major sputterdeposition parameters in a controlled manner. In addition, attention is seldom paid to the deposition itself and to the level of oxygen contamination.

The main objective of this experiment is to study how the four main controllable parameters in the given rf sputter-

\footnotetext{
${ }^{a)}$ Electronic mail: s.silva@ @urrey.ac.uk
}

ing system affect the structural, chemical, and optical properties of the deposited films, and how these parameters affect the actual deposition process.

\section{EXPERIMENT}

\section{A. Growth}

GaN films were deposited using a Nordiko conventional rf reactive sputtering system operating at $13.56 \mathrm{MHz}$. The target was $99.9999 \%$ pure $\mathrm{Ga}$, contained in a $\mathrm{Ni}$ dish on the lower driven electrode which was water cooled. The substrates were attached to the upper electrode by means of steel clips. The substrates used were (001) Si and fused quartz, and these were degreased with organic solvents prior to deposition. The substrate electrode was electrically grounded and could be heated to $450{ }^{\circ} \mathrm{C}$.

The growth chamber was fed by $\mathrm{Ar}$ and $\mathrm{N}_{2}$ gas lines (99.9999\% purity), and the flow rates controlled by 20 SCCM (standard cubic centimeter per minute) mass-flow controllers. A quartz shield surrounded the region between the two electrodes containing the plasma. Before each deposition, the chamber and gas lines were evacuated to a pressure below $3 \times 10^{-4} \mathrm{~Pa}$ by a rotary/diffusion pump combination.

The influence of varying the substrate electrode temperature, the deposition pressure, the $\mathrm{N}_{2}$ : Ar gas ratio, and the target self-bias on the properties of the resulting films was investigated. During a standard deposition, the parameters 
were kept at room temperature, 2.0 Pa, 8:12 SCCM (40\% $\mathrm{N}_{2}$ ), and $-800 \mathrm{~V}$. One parameter was varied at a time, and the changes in the films' properties were measured. Deposition times were adjusted to keep the film thickness close to $100 \mathrm{~nm}$ to allow a better comparison between the various properties. A few thicker films, up to $1 \mu \mathrm{m}$, were also grown for comparison.

\section{B. Measurements}

Film thicknesses were measured using profilometry and ellipsometry at a $632.8 \mathrm{~nm}$ wavelength. Ellipsometry was also used to obtain values for the refractive index. The surface was imaged using a Hitachi S4000 scanning electron microscope (SEM). The surface topography was analyzed using a Digital Instruments, Dimension 3100 atomic force microscope (AFM) operating in the tapping mode. The cross-sectional transmission electron microscopy (TEM) was carried out in a Philips CM200. The relative elemental composition of the films was measured using energy dispersive X-ray (EDX) spectroscopy on a Philips XL30 SEM. Optical absorption spectra of samples deposited on quartz substrates were measured with a Camspec M300 UV-visible spectrophotometer. The biaxial stress was estimated from profilometric measurements of the change in curvature of Si substrates utilizing Stoney's equation. The absorbance spectra of the films were obtained by subtracting the absorbance of the substrate from the total absorbance. Optical band gaps were estimated by extrapolating linear fits to plots of the absorption coefficient $\alpha$ squared versus the photon energy $h \nu$ at the band edge, the standard method for crystalline, direct band gap materials. Urbach tail energies were obtained from the inverse of the gradient of $\ln \alpha$ vs $h \nu$ at the band tail.

\section{RESULTS AND DISCUSSION}

\section{A. General}

Films deposited under standard conditions on quartz have a yellowish tinge. The films become much darker as the nitrogen fraction of the deposition gas is reduced to $10 \%$ and slightly darker when the target bias voltage is increased to very high values. At very low biases, the films appear almost clear and glass like. At $\mathrm{N}_{2}$ fractions of $60 \%$ and above, the films on Si tend to delaminate. The Ga target sometimes melts at high rf powers or during long deposition runs, but the deposition rates are not reduced as would be expected as a result of energy loss in the liquid. ${ }^{14}$

\section{B. Deposition rate}

The deposition rate was calculated by dividing the thickness of the GaN film on Si by the deposition time. These values are plotted in Fig. 1 as functions of the deposition conditions. Profilometric values were used when ellipsometry proved unreliable because of the absorption at the laser wavelength or delamination.

\section{Dependence on substrate electrode temperature}

As the substrate electrode temperature is increased, the deposition rate remains approximately constant at around
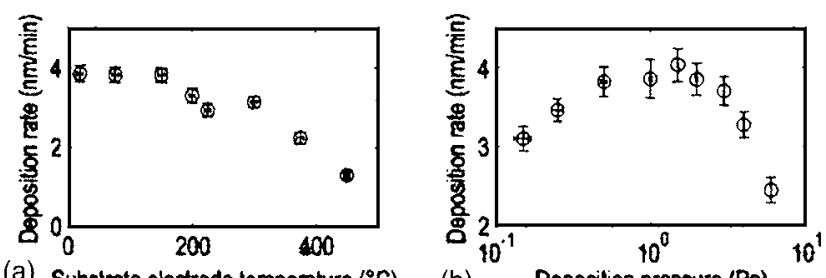

(a) Substrate electrode temperature $\left({ }^{\circ} \mathrm{C}\right)$
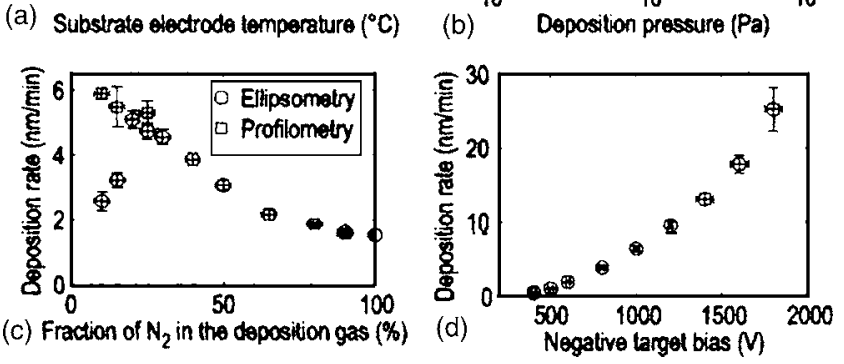

(d)

Negative target bias $(M)$

FIG. 1. Deposition rate as a function of deposition conditions.

$3.8 \mathrm{~nm} / \mathrm{min}$ until $150^{\circ} \mathrm{C}$, after which it decreases with temperature, reaching $1.3 \mathrm{~nm} / \mathrm{min}$ at $450{ }^{\circ} \mathrm{C}$. Factors which may affect the deposition rate include the adsorption and desorption rates of $\mathrm{Ga}$ and $\mathrm{N}$ atoms and their mobilities on the $\mathrm{GaN}$ growth surface, the rate of the $\mathrm{Ga}+\mathrm{N} \rightarrow \mathrm{GaN}$ reaction, and the heat radiated to the target surface.

Since the drop in the deposition rate cannot be attributed to the densification of the film, it is concluded that the net rate of deposition of both $\mathrm{Ga}$ and $\mathrm{N}$ atoms is reduced at higher temperatures. One possible explanation is that adatoms are desorbed more rapidly at higher substrate temperatures. The rate at which atoms are incorporated into the growing film is

$$
\begin{aligned}
R_{g} & =\left(R_{\mathrm{inc}}-R_{\mathrm{ref}}\right)-R_{\mathrm{des}} \\
& =R_{\mathrm{ads}}-R_{\mathrm{des}},
\end{aligned}
$$

where $R_{\text {inc }}, R_{\text {ref }}, R_{\text {des }}$, and $R_{\text {ads }}$ are, respectively, the rates at which atoms are incident upon, reflected off, desorbed from, and adsorbed onto the substrate. The desorption rate from a layer of adsorbed atoms has the form

$$
R_{\mathrm{des}}=A B e^{-E_{d} / k T},
$$

where $A$ is the fraction of the surface occupied by the layer, $B$ is a frequency factor for desorption from the layer, and $E_{d}$ is the energy required for an atom in the layer to overcome the surface forces. ${ }^{15}$ If it is assumed that the adsorption rate and the adatom coverage of the substrate do not change substantially with temperature, the (atomic) deposition rate can be written as

$$
R_{g}=r_{0}\left(1-d_{0} e^{-E_{d} / k T}\right),
$$

where $r_{0}$ is the deposition rate at low temperatures and $d_{0}$ $=A B / r_{0}$.

Since the density is essentially constant with the temperature, the spatial deposition rate should also take this form. Fitting Eq. (4) to the data of Fig. 1(a) gives values of $r_{0}=3.85 \mathrm{~nm} / \mathrm{min}, d_{0}=20.4$, and $E_{d}=0.22 \mathrm{eV}$.

This fit suggests that the deposition rate should drop to zero above about $550{ }^{\circ} \mathrm{C}$, but this is unlikely to occur since the surface coverage term $A$ should be reduced for very high desorption rates. If the value of $E_{d}$ is compared with values 
in the literature, $\mathrm{Al}$ adatoms on $\mathrm{NaCl}$ and mica have adsorption energies of 0.6 and $0.9 \mathrm{eV}$, respectively. ${ }^{16}$ The values for Ga may be comparable because it is chemically similar and has a slightly lower bulk binding energy. However, the few values for $\mathrm{Ga}$ adsorbed onto $\mathrm{GaN}$ reported in the literature are considerably higher. Guha et al. ${ }^{17}$ reported a measured $E_{d}$ value of $2.2 \pm 0.2 \mathrm{eV}$ for less than one monolayer of $\mathrm{Ga}$ adsorbed onto a GaN (001) surface. Adelmann et al. ${ }^{18}$ calculated from first principles that the adatom binding energies for single atoms and adatom islands on top of an adsorbed Ga bilayer were 2.52 and $2.41 \mathrm{eV}$, respectively. It is not possible to connect the $E_{d}$ value extracted in the present study with other activation energies in the system, such as the cohesive energy of bulk Ga [2.8 eV (Ref. 19)] or the activation energy for the evaporation of $\mathrm{GaN}$ [3.6 eV (Ref. 20)]. One possibility, which has been overlooked, is that the temperature of the growth face, where adsorption/desorption occurs, may be substantially higher than the temperature of the substrate electrode or the substrate itself. This would effectively shift the plot of Fig. 1(a) to higher temperatures and thus increase the value of $E_{d}$ considerably.

\section{Pressure dependence}

As the deposition pressure is increased [Fig. 1(b)], the deposition rate increases from $3.1 \mathrm{~nm} / \mathrm{min}$ at $0.15 \mathrm{~Pa}$, reaches a broad maximum of about $3.9 \mathrm{~nm} / \mathrm{min}$ in the range 0.5-2.0 Pa, and then decreases again to $2.4 \mathrm{~nm} / \mathrm{min}$ at 6.0 $\mathrm{Pa}$. The pressure dependence of the deposition rate is likely to be a result of two competing processes. As the pressure is increased, there are more and more gas atoms/ molecules available for ionization which should increase the number of ions attracted to the target and thus increase the deposition rate. However, at the same time, the mean free path of electrons in the plasma is reduced, lowering the average electron energy. This serves to reduce the probability of an atom being ionized by a collision, and thus the number of ions available for sputtering. The reduced mean free path also applies to the sputtered Ga species which means that less of the sputtered material reaches the substrate. The mean free path of unionized gas particles at $25^{\circ} \mathrm{C}$ and $1.0 \mathrm{~Pa}$ is $7 \mathrm{~mm}$, and the total target-substrate distance is around $50 \mathrm{~mm}$. For these reasons, the deposition rate is maximized near $1 \mathrm{~Pa}$.

\section{Nitrogen fraction dependence}

The deposition rate decreases approximately linearly with increasing $\mathrm{N}_{2}$ fraction, from around $5.9 \mathrm{~nm} / \mathrm{min}$ at $10 \%$ $\mathrm{N}_{2}$ to around $2.1 \mathrm{~nm} / \mathrm{min}$ at $65 \% \mathrm{~N}_{2}$ [Fig. 1(c)]. Thereafter, it decreases more slowly but also linearly to around $1.5 \mathrm{~nm} / \mathrm{min}$ at $100 \% \mathrm{~N}_{2}$. Dependencies of the deposition rate versus the reactive gas fraction showing an initial rapid decrease followed by a more gradual one have been observed in other material systems such as TaN, ${ }^{21} \mathrm{TiN},{ }^{22} \mathrm{RuO}_{2}{ }^{23}$ and $\mathrm{CrN} / \mathrm{Cr}_{2} \mathrm{~N}^{24}$ The rapid drop is usually ascribed to the formation of a layer of compound on the target. For sputtered GaN films, Ross and Rubin ${ }^{25}$ observed an almost identical dependence to this experiment at $1.22 \mathrm{~Pa}$, including a knee in the data at $65 \% \mathrm{~N}_{2}$. Lakshmi et al. ${ }^{6}$ also observed a simi- lar dependence with a few data points and concluded that it was Ar which was mainly responsible for sputtering.

Heller $^{26}$ has modeled the effect on the sputtering rate of the surface oxide formation on the target under the assumption that the sputter yields of the reactive and sputtering gases are identical. At low partial pressures of the reactive gas, the target surface is clean and the sputtering rate is high (that of the metal in the sputtering gas). At a critical partial pressure $P^{*}$, which is a function of the particular sputtering system, total pressure, and rf power, a layer of compound forms on the target, dramatically reducing the sputtering rate because of the lower sputter yield. Hereafter, the deposition rate decays slowly to a limiting value which is that of a compound target.

According to this model there are two possibilities which depend on the precise forms of curves describing the reaction rate at the target surface and the sputtering rate, both as a function of compound thickness. They both start off with a Ga sputtering rate independent of the partial pressure of the reactive gas until a critical pressure at which the sputter rate equals the reaction rate and a compound forms on the target surface. Hereafter, the sputtering rate decreases slowly in an exponential like manner (type 1) or very rapidly (type 2) to the rate at which the nitride is sputtered.

Since the sputter yield changes with the sputtering ion, the sputtering rate of $\mathrm{Ga}$ in $\mathrm{N}_{2}$ will be different from that in Ar. In addition, if GaN forms on the target, sputter yields in Ar and $\mathrm{N}_{2}$ will once again be different. Thus, there are four different sputtering rates, namely, those of $\mathrm{Ga}$ in $\mathrm{Ar}, \mathrm{Ga}$ in $\mathrm{N}_{2}, \mathrm{GaN}$ in $\mathrm{Ar}$, and $\mathrm{GaN}$ in $\mathrm{N}_{2}$, denoted as $R_{\mathrm{Ga}: \mathrm{Ar}}, R_{\mathrm{Ga}: \mathrm{N}_{2}}$, $R_{\mathrm{GaN}: \mathrm{Ar}}$, and $R_{\mathrm{GaN}: \mathrm{N}_{2}}$, respectively. If it is assumed that the process taking place here is of type 2 , with the decrease in sputtering rate approximating a step change, the deposition rate can be written as

$$
\begin{aligned}
R_{\mathrm{dep}}= & {\left[x R_{\mathrm{Ga}_{\mathrm{N}}}+(1-x) R_{\mathrm{Ga}: \mathrm{Ar}}\right] u\left(x_{0}-x\right) } \\
& +\left[x R_{\mathrm{GaN}_{2} \mathrm{~N}_{2}}+(1-x) R_{\mathrm{GaN}: \mathrm{Ar}}\right] u\left(x-x_{0}\right),
\end{aligned}
$$

where $x$ is the fraction of $\mathrm{N}_{2}$ in the sputtering gas, $u(x)$ is the Heaviside function, and $x_{0}$ is the nitrogen fraction at which the step change occurs. This fit to the data of Fig. 1(c) produces values of $R_{\mathrm{Ga}: \mathrm{Ar}}=6.5, R_{\mathrm{Ga}: \mathrm{N}_{2}}=-0.3, R_{\mathrm{GaN}: \mathrm{Ar}}=3.3$, and $R_{\mathrm{GaN}: \mathrm{N}_{2}}=1.5 \mathrm{~nm} / \mathrm{min}$, and $x_{0}=0.64$. The value for $R_{\mathrm{Ga}: \mathrm{N}_{2}}$ is obviously incorrect, but it could be due to a change in the efficiency of ion formation, with increasing $\mathrm{N}_{2}$ concentration affecting the slope of the first section of the curve. However, it does emphasize the dominance of $\mathrm{Ga}$ sputtering in $\mathrm{Ar}$, when compared with $\mathrm{Ga}$ sputter rates in $\mathrm{N}_{2}$. It is also suspicious that $R_{\mathrm{Ga}: \mathrm{N}_{2}}<R_{\mathrm{GaN}: \mathrm{N}_{2}}$. However, $R_{\mathrm{Ga}: \mathrm{Ar}}>R_{\mathrm{GaN}: \mathrm{Ar}}$ and $R_{\mathrm{GaN}: \mathrm{Ar}}>R_{\mathrm{GaN}: \mathrm{N}_{2}}$, as expected. It has not been possible to find relative values of the sputter yields in the literature with which to compare these values.

Another possibility is that the curve is actually of type 1, but with $x_{0}$ shifted to very low $\mathrm{N}_{2}$ concentrations and having an exponentiallike dependence, but this function cannot be expressed analytically for fitting.

The model of Hrbek, ${ }^{27}$ based on a reduction in sputtering rate as a result of increased adsorption (but not reaction) of the reactive gas at the target surface, provides a poor fit to 

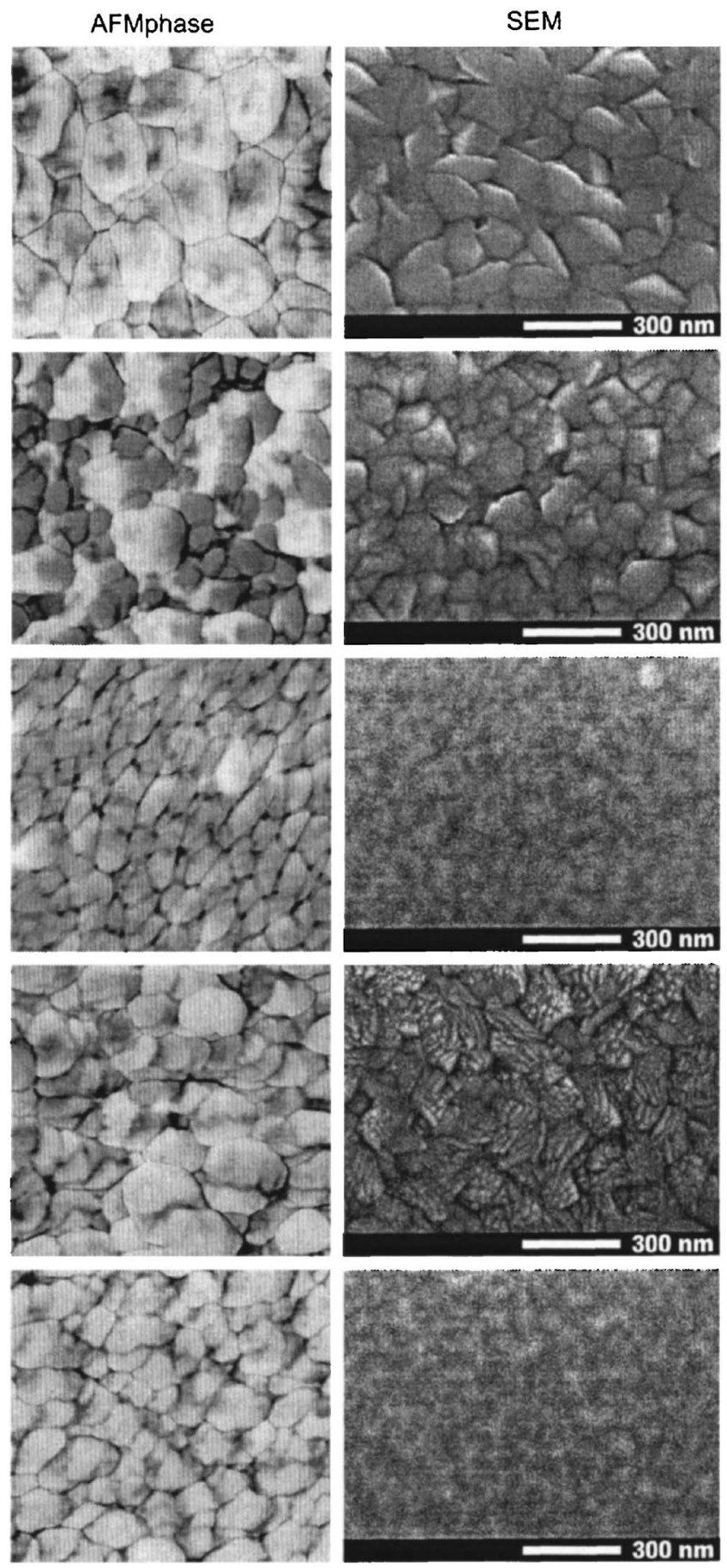

FIG. 2. AFM phase and SEM images of $1 \mu \mathrm{m}$ films deposited at (a) $-600 \mathrm{~V}$, (b) standard conditions (room temperature, 2.0 $\mathrm{Pa}, 40 \% \mathrm{~N}_{2}$, and $-800 \mathrm{~V}$ ), (c) $-1200 \mathrm{~V}$, (d) $200{ }^{\circ} \mathrm{C}$, and (e) $20 \% \mathrm{~N}_{2}$. All scales are the same.

the data. In addition, a scum (presumably GaN) was often observed on the target when depositing at low sputter rates. However, this effect would increase the gradient of the low $\mathrm{N}_{2}$ fraction part of the observed curve, which could explain the erroneous values of the earlier fit.

\section{Target bias dependence}

The deposition rate increases roughly quadratically with the target bias voltage from about $0.47 \mathrm{~nm} / \mathrm{min}$ at $-400 \mathrm{~V}$ to around $25 \mathrm{~nm} / \mathrm{min}$ at $-1800 \mathrm{~V}$ [Fig. 1(d)]. If it is assumed
TABLE I. The surface roughness and area smoothness calculated from the AFM amplitude deposition condition. $R_{q}, R_{a}$ and $A_{n}$ represent, the RMS roughness, the mean roughness and normalized surface area above a threshold value, respectively.

\begin{tabular}{lccccc}
\hline \hline & $-600 \mathrm{~V}$ & $-800 \mathrm{~V}$ & $-1200 \mathrm{~V}$ & $200{ }^{\circ} \mathrm{C}$ & $20 \% \mathrm{~N}_{2}$ \\
\hline$R_{q}(\mathrm{~nm})$ & 9.3 & 6.8 & 2.8 & 6.3 & 2.8 \\
$R_{a}(\mathrm{~nm})$ & 7.4 & 5.1 & 2.2 & 4.6 & 2.2 \\
$A_{n}(\%)$ & 3.0 & 2.7 & 1.3 & 1.5 & 0.7 \\
\hline \hline
\end{tabular}

that the system used here is comparable to the dc sputtering process and that the ion sheath is predominantly collisionfree, the Child-Langmuir law gives the ion current incident on the Ga target as proportional to $V^{3 / 2}$, where $V$, the voltage across the sheath, is taken to be approximately the same as the target bias voltage. ${ }^{14}$ The sputter yield as a function of ion energy can be divided into three regions. ${ }^{28}$ The first, from the threshold to $100 \mathrm{eV}$, where there is a poor experimental reproducibility, will not be discussed. In the second, from 100 to $600 \mathrm{eV}$, the yield is approximately proportional to $V$, and in the third region, above $600 \mathrm{eV}$, it drops to $V^{1 / 2}$. If the dependencies of the ion current and the sputter yield are combined, the rates at which the material is removed from the target in the latter two regions are then proportional to $V^{5 / 2}$ and $V^{2}$, respectively. Since both of these fit well to the experimental data, the film growth rate is assumed to be controlled primarily by the rate at which $\mathrm{Ga}$ is sputtered.

\section{Crystal structure}

The AFM phase and SEM images of selected $1 \mu \mathrm{m}$ samples on Si are shown in Fig. 2 at the same magnification. The phase images were found to be especially useful for showing grain boundaries. The surface roughness and area calculated from the AFM amplitude plots are given in Table I. For the sample deposited at $-600 \mathrm{~V}$, crystallites are well defined and protrude from the substrate. The grain sizes are as large as $250 \mathrm{~nm}$ in diameter. At $-800 \mathrm{~V}$, the crystallites are smaller and more variable in size, and at $-1200 \mathrm{~V}$, the sample is very flat and the crystallites uniformly small. The rms roughness decreases from $9.3 \mathrm{~nm}$ for the $-600 \mathrm{~V}$ sample to $2.8 \mathrm{~nm}$ for the $-1200 \mathrm{~V}$ sample. This trend towards a reduction in the crystallite size and surface roughness is mirrored in $100 \mathrm{~nm}$ samples deposited every $200 \mathrm{~V}$ between -400 and $-1400 \mathrm{~V}$. However, the surface features are much smaller than for the $1 \mu \mathrm{m}$ samples. Films may be more crystalline at low deposition biases because the deposition rates and the energies of most particles in the system are lower. Thus, adatoms can move about the surface for a longer time without being covered by incoming atoms, and there should be less damage to the growing crystallites by incoming particles.

The $1 \mu \mathrm{m}$ sample deposited at $200{ }^{\circ} \mathrm{C}$ shows similar grain sizes to those of the room-temperature deposited sample, but there are what appear to be many fissures on the surface of each grain. SEM images of $100 \mathrm{~nm}$ films at 18, 150,300 , and $450{ }^{\circ} \mathrm{C}$ appear to show a grain size increase as a function of temperature, but films are smoother than those deposited at low bias voltages. For a $20 \% \mathrm{~N}_{2}$ fraction during 


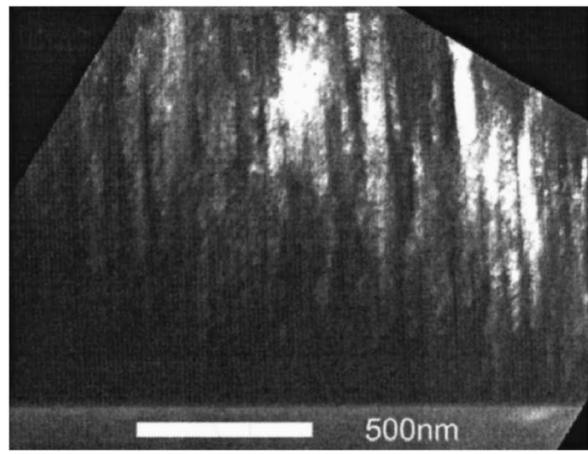

FIG. 3. Dark-field cross-sectional TEM image of $20 \% \mathrm{~N}_{2}$ film showing a columnar morphology.

growth, the surface is as smooth as the $-1200 \mathrm{~V}$ sample, but the $1 \mu \mathrm{m}$ sample has the smallest normalized surface area of all the thick samples. At higher $\mathrm{N}_{2}$ concentrations $(60 \%$, $80 \%$, and $100 \%$ ), the $100 \mathrm{~nm}$ film surface becomes increasingly featureless.

Although it was not possible to grow a $1 \mu \mathrm{m}$ sample at $0.5 \mathrm{~Pa}$ because the sample delaminated completely during deposition, images of $100 \mathrm{~nm}$ samples deposited at 0.15 and $0.5 \mathrm{~Pa}$ show a surface too smooth to image properly. The greater mean free path of atoms at lower pressures means that particles hit the substrate with increased energy, possibly producing an increasingly stressed and disordered film. A $100 \mathrm{~nm}$ sample deposited at $6.0 \mathrm{~Pa}$ shows essentially the same surface morphology as that of the $2.0 \mathrm{~Pa}$ sample.

Cross-sectional TEM characterization showed that in most cases, the crystallites are columnar in shape, with the column width increasing towards the top surface of the film. This is in agreement with the trend observed using SEM. The presence of many spots forming discontinuous rings on the selected area diffraction (SAD) patterns showed that the films are polycrystalline although the degree of crystallinity differs. The relative spacing of the rings show that the material is predominantly wurtzite GaN.

The TEM samples exhibiting the greatest crystallinity are $1 \mu \mathrm{m}$ thick, deposited at $20 \% \mathrm{~N}_{2}$ and $200{ }^{\circ} \mathrm{C}$. They have large, clear grains which start right at the substrate-sample interface and reach up to 60 and $100 \mathrm{~nm}$ in diameter at the top surface. This value for the $200{ }^{\circ} \mathrm{C}$ samples is smaller than that shown by the AFM phase image. The discrepancy may either be a result of the way in which the sample has been sectioned or it may mean that what appear to be single crystallites in the AFM image are, in fact, groups of crystallites. The SAD patterns close to the surface of the $20 \% \mathrm{~N}_{2}$ film show an array of clear spots, which suggests that there are only a few large crystallites in the region of observation. For the $200{ }^{\circ} \mathrm{C}$ sample, the SAD pattern shows bright continuous arcs which may indicate a gradual change in orientation within a crystallite or a range of crystallite orientations about a preferred orientation. The columnar grain structure of the $20 \% \mathrm{~N}_{2}$ film is shown in Fig. 3, where the dark-field TEM image was obtained by selecting individual GaN reflections.

Thin films deposited at $450{ }^{\circ} \mathrm{C}$ and $0.25 \mathrm{~Pa}$ are very disordered. The $450{ }^{\circ} \mathrm{C}$ sample has crystallites of the order

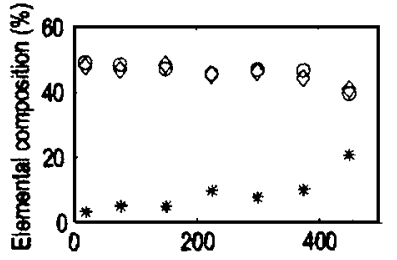

(a) Substrale electrode temperature $\left({ }^{\circ} \mathrm{C}\right)$

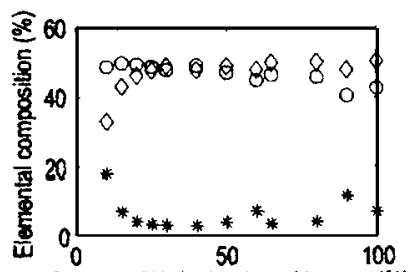

(c)
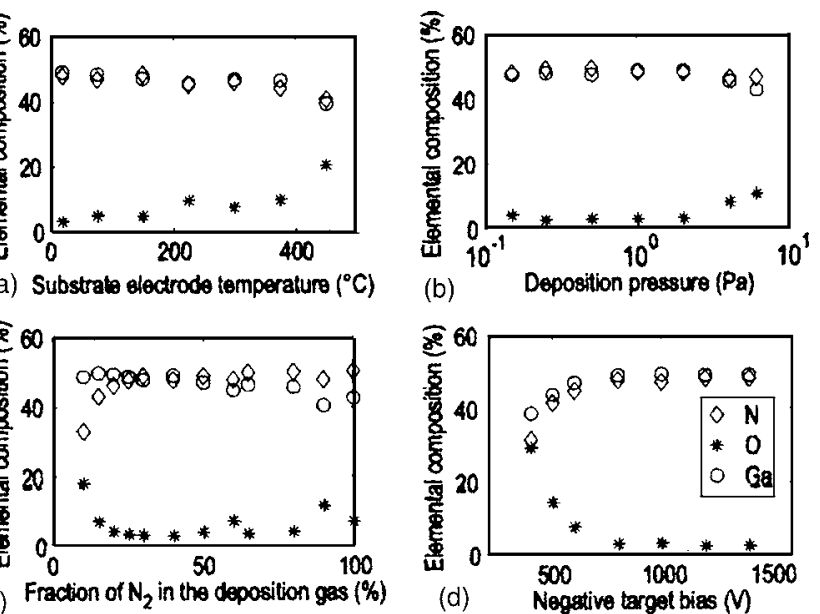

(b)
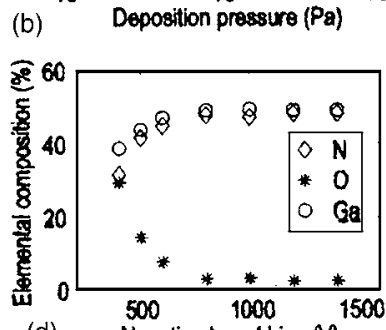

(d)

FIG. 4. Relative elemental composition of $100 \mathrm{~nm}$ films.

of $5 \mathrm{~nm}$, no obvious columnar growth, and a diffused SAD pattern. The $0.25 \mathrm{~Pa}$ sample is also extremely disordered, as shown by an even less well defined SAD pattern, but the high resolution TEM images do show lattice fringes and there are some column like illuminated areas in the dark-field images.

\section{Chemical composition}

The elemental composition of samples was obtained using EDX. For this analysis, the SEM accelerating voltage was lowered to $4 \mathrm{kV}$ for the $100 \mathrm{~nm}$ samples to reduce the electron penetration depth such that the X-ray peak from the Si substrate was all but invisible. Thicker samples were measured at $10 \mathrm{kV}$. A calibration to prevent under-reporting of $\mathrm{O}$ and $\mathrm{N}$ concentrations was carried out on sapphire and high quality, metal-organic chemical-vapor deposition (MOCVD)-grown GaN.

The quartz shield surrounding the plasma was found to be essential in reducing the oxygen contamination of the films. Under standard deposition conditions, the $\mathrm{O}$ content of $500 \mathrm{~nm}$ thick films increased on removal of the shield from 3 to 26 at. \%, irrespective of whether the target was presputtered. A possible reason is that the plasma is not contained without the shield, filling the entire deposition chamber. Thus, a contact with the plasma may release a steady supply of adsorbed gases such as water and oxygen, which are readily incorporated into the growing film. The relative atomic percentages of $\mathrm{Ga}, \mathrm{N}$, and $\mathrm{O}$ in the samples are plotted in Fig. 4. As a function of the substrate electrode temperature, the oxygen content increases monotonically from 3.2 at. $\%$ at room temperature to $9.7 \%$ at $375^{\circ} \mathrm{C}$ and $20.3 \%$ at $450{ }^{\circ} \mathrm{C}$. The ratio of $\mathrm{Ga}: \mathrm{N}$ is essentially constant at around $1: 1$. As a function of pressure, there is a region in the range 0.25-2.0 Pa, where the $\mathrm{O}$ contamination changes only slightly from $2.8 \%$ to $3.3 \%$. At lower and higher pressures, the $\mathrm{O}$ content increases. At $0.15 \mathrm{~Pa}$, it is $4.4 \%$, and at 4.0 and $6.0 \mathrm{~Pa}, 8.2 \%$ and $10.8 \%$, respectively. As a function of the $\mathrm{N}_{2}$ flow rate, the $\mathrm{O}$ concentration increases at both low and high flow rates. As the $\mathrm{N}_{2}$ flow rate is increased, the $\mathrm{O}$ concentration in the film changes rapidly from 18.2 at. $\%$ at $10 \%$ $\mathrm{N}_{2}$ to a shallow minimum at $40 \% \mathrm{~N}_{2}$, before increasing 


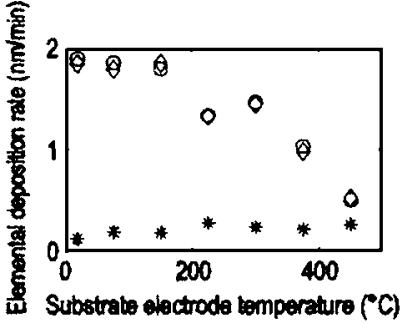

(a)

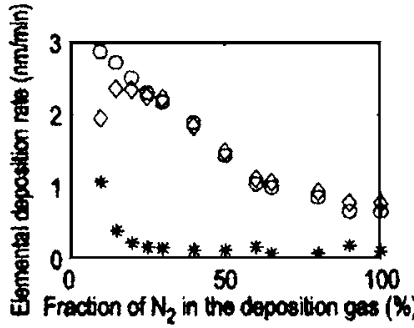

(c)

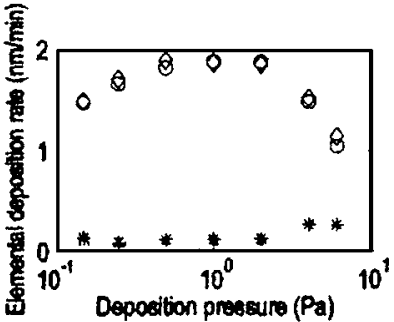

(b)

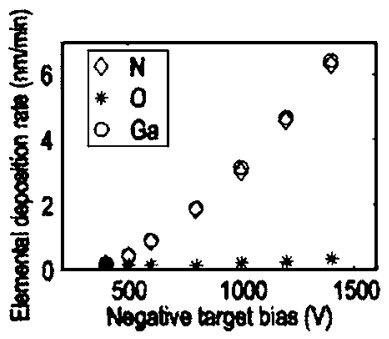

(d)
FIG. 5. Elemental deposition rate obtained by multiplying the atomic fraction of a specific element by the deposition rate.

slowly to about 7 at. $\%$ at $100 \% \mathrm{~N}_{2}$. The $\mathrm{N} / \mathrm{Ga}$ ratio increases from 0.68 at $10 \% \mathrm{~N}_{2}$ to 1.18 at $100 \% \mathrm{~N}_{2}$. The value at $40 \% \mathrm{~N}_{2}$, with the $\mathrm{O}$ minimum, is 0.98 . The high $\mathrm{Ga}$ concentration at low $\mathrm{N}_{2}$ flow rates has often been measured or inferred in the literature. $5,6,25$

The most dramatic change in the level of oxygen contamination is as a function of the target bias. At $-400 \mathrm{~V}$, this is about 30 at. $\%$ but decreases rapidly to around $3.2 \%$ at $-800 \mathrm{~V}$, after which it decreases very slightly to $2.6 \%$ at $-1400 \mathrm{~V}$. The $\mathrm{N} / \mathrm{Ga}$ ratio is fairly constant, except at low biases where it decreases from 0.98 at $-800 \mathrm{~V}$ to 0.82 at $-400 \mathrm{~V}$

If the nitrogen in sections of the film were replaced with oxygen so as to form $\mathrm{Ga}_{2} \mathrm{O}_{3}$, it would do so such that the relationship between the $\mathrm{Ga}, \mathrm{N}$, and $\mathrm{O}$ atomic percentages would be $d\left(\mathrm{Ga}_{\text {at. } \%}-\mathrm{N}_{\text {at. } \%}\right) / d \mathrm{O}_{\text {at. } \%}=2 / 3$. However, this is not observed for these films. At high temperatures, there is no change in the Ga: $\mathrm{N}$ ratio and at high pressures, perhaps even a slight increase in the concentration of nitrogen relative to gallium. At low target biases, there is a slight reduction in the Ga: $\mathrm{N}$ ratio, but the change is only about $1 / 3$ of the expected value. Thus, $\mathrm{O}$ does not simply replace $\mathrm{N}$, nor is it incorporated as $\mathrm{Ga}_{2} \mathrm{O}_{3}$.

If it is assumed that the atomic density (atoms $/ \mathrm{nm}^{3}$ ) is approximately constant under all the deposition conditions, it is possible to obtain a sort of elemental deposition rate for each constituent element by multiplying the spatial deposition rate by the relative atomic fraction of the film. This allows the rate at which each individual element is incorporated into the growing film to be determined. The elemental deposition rates for $\mathrm{Ga}, \mathrm{N}$, and $\mathrm{O}$ are plotted in Fig. 5 .

As a function of temperature, the $\mathrm{O}$ deposition rate increases from 0.12 to $0.26 \mathrm{~nm} / \mathrm{min}$, while the $\mathrm{Ga}$ and $\mathrm{N}$ rates decrease from 1.9 to $0.5 \mathrm{~nm} / \mathrm{min}$. This suggests that the increased $\mathrm{O}$ concentration at elevated temperatures is partially a result of the low $\mathrm{Ga}$ and $\mathrm{N}$ deposition rates which would allow a fixed absolute $\mathrm{O}$ incorporation rate to result in an increased relative concentration in the deposited film. The increased absolute $\mathrm{O}$ incorporation rate is thought to be caused by an accelerated desorption of $\mathrm{O}_{2}$ and $\mathrm{H}_{2} \mathrm{O}$ off parts of the deposition chamber adjacent to the heater.

The $\mathrm{O}$ deposition rate is essentially constant at $0.12 \mathrm{~nm} / \mathrm{min}$ for deposition pressures from $0.15-2.0 \mathrm{~Pa}$, but jumps to around $0.27 \mathrm{~nm} / \mathrm{min}$ for depositions at 4.0 and 6.0 Pa. At these higher pressures, a significant amount of arcing takes place between the target and the earth shield, possibly releasing additional $\mathrm{H}_{2} \mathrm{O}$ and $\mathrm{O}_{2}$ because of local heating. A reduction in the amount of available atomic $\mathrm{N}$ might increase the $\mathrm{O}$ incorporation, but this is unlikely because the $\mathrm{N} / \mathrm{Ga}$ ratio increases slightly at higher pressures. Thus, the $\mathrm{O}$ incorporation rate is essentially constant where there is no arcing, and the reduction in the Ga deposition rate at high and low pressures increases the $\mathrm{O}$ contamination of the films. It appears that the increased energy of sputtered atoms reaching the substrate at lower pressures (because of fewer collisions) does not have the effect of removing adsorbed $\mathrm{O}$ atoms, as was thought to occur by Zembutsu and Kobayashi, ${ }^{7}$ where a negative substrate bias reduced the amount of $\mathrm{O}$ incorporation because of ion bombardment.

As the $\mathrm{N}_{2}$ fraction in the deposition atmosphere is increased from $10 \%$ to $100 \%$, the $\mathrm{O}$ concentration initially decreases from 18.2 at. $\%$ at $10 \% \mathrm{~N}_{2}$ to 3.2 at. $\%$ at $40 \% \mathrm{~N}_{2}$. In the same range, the $\mathrm{N}$ concentration increases from 33.1 to 47.8 at. $\%$. The relationship between the $\mathrm{Ga}, \mathrm{N}$, and $\mathrm{O}$ atomic percentages in this region is $d\left(\mathrm{Ga}_{\mathrm{at} . \%}-\mathrm{N}_{\text {at. \% }}\right) /$ $d \mathrm{O}_{\text {at. } \%}=0.95$. Thus, it appears that the missing $\mathrm{N}$ atoms are replaced by $\mathrm{O}$ atoms. The $\mathrm{O}$ incorporation rate is decreased from $1.07 \mathrm{~nm} / \mathrm{min}$ at $10 \% \mathrm{~N}_{2}$ to $0.12 \mathrm{~nm} / \mathrm{min}$ at $40 \% \mathrm{~N}_{2}$. This high incorporation rate at low $\mathrm{N}_{2}$ ratios is ascribed to gettering of the available $\mathrm{O}$ in the deposition atmosphere in the absence of sufficient atomic $\mathrm{N}$. At higher $\mathrm{N}_{2}$ concentrations, the $\mathrm{O}$ concentration increases slowly, reaching around 7 at. $\%$ at $100 \% \mathrm{~N}_{2}$, but since the $\mathrm{O}$ incorporation rate is fairly constant in this region, it is likely that this increase is due to the decreased deposition rate.

As a function of the target bias voltage, the increase in the $\mathrm{Ga}$ and $\mathrm{N}$ deposition rate is more than ten times that of the $\mathrm{O}$ deposition rate. From -400 to $-800 \mathrm{~V}$, the absolute $\mathrm{O}$ incorporation rate is more or less constant, after which it increases slowly up to $-1400 \mathrm{~V}$. This is interpreted to mean that at medium to low target bias, the increase in relative $\mathrm{O}$ contamination with a reduction in bias voltage is due to the reduction in $\mathrm{Ga}$ and $\mathrm{N}$ deposition rates and a constant $\mathrm{O}$ incorporation rate. At higher bias, the relative oxygen contamination continues to decrease, but this is only because the absolute $\mathrm{Ga}$ and $\mathrm{N}$ incorporation rates increase at a much greater rate than the absolute $\mathrm{O}$ incorporation rate. The increase in the absolute $\mathrm{O}$ incorporation rate is ascribed to the increased energy of the plasma increasing desorption from the chamber walls.

The trends in the $\mathrm{O} / \mathrm{N}$ ratio measured using electronenergy-loss spectroscopy (EELS) in the TEM agree with the trends reported here using EDX in the SEM. Oxygen contamination of GaN samples deposited by reactive sputtering has been reported a number of times in the literature with values of up to $5,{ }^{29} 9,{ }^{30} 15,,^{31}$ and 20 at. $\% .^{7}$ In the one case 


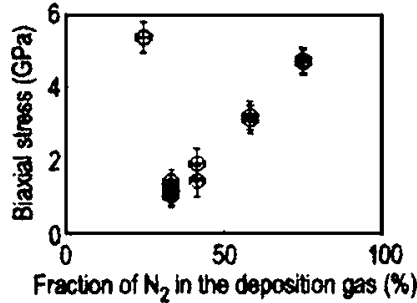

(a)

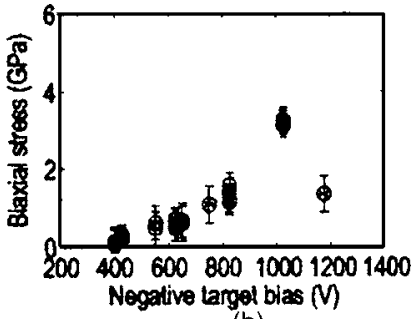

(b)
FIG. 6. Compressive biaxial stress in $100 \mathrm{~nm}$ films on $\mathrm{Si}$ as a function of (a) $\mathrm{N}_{2}$ : Ar flow ratios and (b) the negative target bias voltage.

where the $\mathrm{H}$ concentration was also measured, ${ }^{31}$ the $\mathrm{H}$ and $\mathrm{O}$ contamination levels were almost the same at 16 and 15 at. \%, respectively. Although the source of $\mathrm{H}$ was ascribed to the contamination of the source gases, it is speculated that it could be due to the desorption of $\mathrm{H}_{2} \mathrm{O}$ off the chamber walls.

\section{E. Biaxial stress}

The biaxial stress was measured in an earlier experiment, and as a function of the target bias and deposition nitrogen fraction, where the pressure was $1.85 \mathrm{~Pa}$, the $\mathrm{N}_{2}$ fraction is $33 \%$, and the top electrode is floating. The values of the compressive biaxial stress are plotted in Fig. 6. There appears to be a fairly linear increase in biaxial stress from $1.2 \mathrm{GPa}$ at $33 \% \mathrm{~N}_{2}$ to $4.7 \mathrm{GPa}$ at $75 \% \mathrm{~N}_{2}$. This increase may be responsible for the delamination of films deposited at $60 \%$ $\mathrm{N}_{2}$ and above. As the target bias is increased, the stress also increases from around $0.1 \mathrm{GPa}$ at $-400 \mathrm{~V}$ to $3.2 \mathrm{GPa}$ at $-1025 \mathrm{~V}$. The reason for this may be the increased energy of sputtered atoms at higher target biases impacting on the growing film, or it may be because at the high deposition rates, there is insufficient time for incoming atoms to take up optimal positions in the film before they are covered with more materials. No delamination was observed at high biases for $100 \mathrm{~nm}$ films, possibly because the increased energy of particles hitting the target causes some substrate-film mixing or relaxation at high fluxes. In the current experiment, it is also thought that films deposited at low pressures have an increased biaxial stress because the larger mean free path means that particles have higher energies. When a $1 \mu \mathrm{m}$ thick film was grown at $0.5 \mathrm{~Pa}$, the film delaminated during deposition, whereas the others, at high $\mathrm{N}_{2}$ flow rates, usually delaminated slowly afterwards.

\section{F. Optical properties}

\section{General}

Fairly typical absorption spectra of films deposited at different temperatures are plotted in Fig. 7(a) and the absorption coefficient squared in 7(b). At low photon energies, up to around $2.4-3.4 \mathrm{eV}$, the dominant feature is interference because of internal reflections within the films. The fundamental absorption at the band edge takes place at higher photon energies for the samples deposited at the higher temperatures. The increased $\mathrm{O}$ concentration shown by EDX may be responsible since the band gap of $\beta-\mathrm{Ga}_{2} \mathrm{O}_{3}$ is in the range $4.7-4.9 \mathrm{eV},{ }^{32-34}$ as compared with the $3.4 \mathrm{eV}$ of $\mathrm{GaN}$.

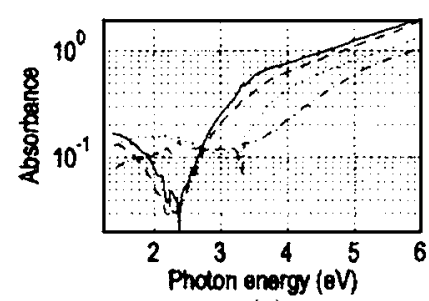

(a)

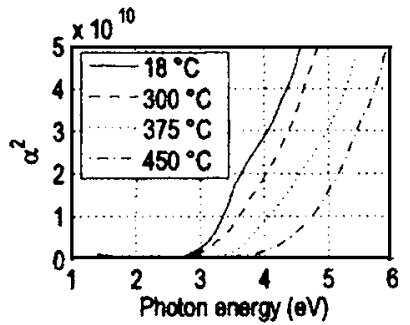

(b)
FIG. 7. Total absorbance of the film and substrate (a) and absorption coefficient squared (b) at various substrate electrode deposition temperatures.

The curves of Fig. 7(b) are remarkably similar to those observed by Butcher et al. ${ }^{35}$ for an increased $\mathrm{O}$ contamination in GaN deposited by remote-plasma enhanced CVD. For the current experiment, plots for decreasing target bias voltages, which have increasing $\mathrm{O}$ contamination levels, exhibit the same trend. This adds weight to the view that $\mathrm{O}$ contamination has a major effect on the optical absorption spectrum close to the band edge.

\section{Band gaps}

The optical band gaps are plotted versus the deposition parameters in Fig. 8. As a function of the substrate electrode temperature, the band gaps increase from $3.02 \mathrm{eV}$ at room temperature to $3.60 \mathrm{eV}$ at $450{ }^{\circ} \mathrm{C}$. The rate of change is low to around $200{ }^{\circ} \mathrm{C}$ and increases thereafter. The increase is primarily ascribed to a shift of absorption to higher photon energies because of an increase in the $\mathrm{O}$ content of the films. Some of the initial increase may be partially due to the improved crystallinity and reduced band tailing because of the increased thermal energy allowing $\mathrm{Ga}$ and $\mathrm{N}$ atoms to migrate over the surface during growth and take up more optimal positions in the growing film.

As a function of the $\mathrm{N}_{2}$ fraction, the band gap initially increases very rapidly from $2.49 \mathrm{eV}$ at $10 \% \mathrm{~N}_{2}$ to a plateau above $25 \% \mathrm{~N}_{2}$ at around $3.07 \mathrm{eV}$ and then increases again above $70 \% \mathrm{~N}_{2}$. The initial band gap increase corresponds to a visible change from dark brown or black to a slightly yellowish color in transmission. In view of the EDX results, this is ascribed to a reduction in the amount of excess $\mathrm{Ga}$ in the
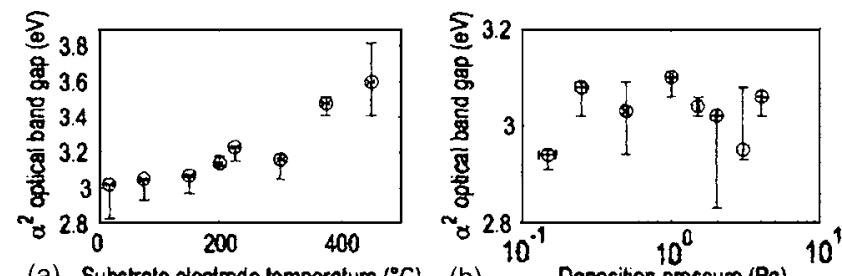

(a) Substrale electrode temperature $\left({ }^{\circ} \mathrm{C}\right)$ (b)
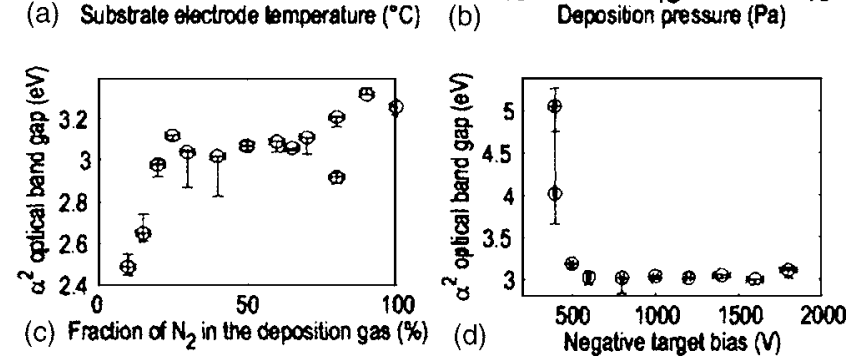

FIG. 8. Optical band gaps for $100 \mathrm{~nm}$ films. 


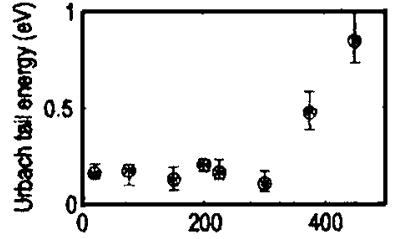

(a) Substrate electrode emperature $\left({ }^{\circ} \mathrm{C}\right)$
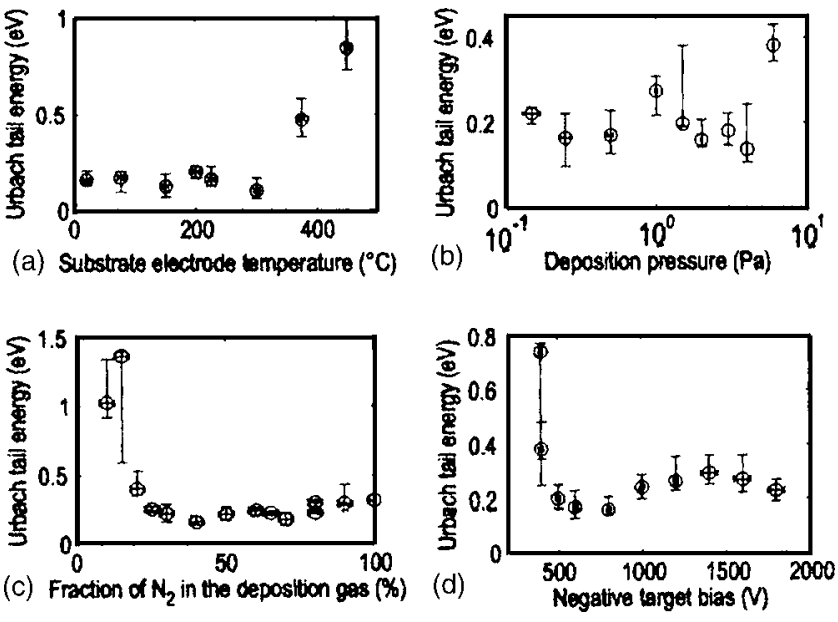

FIG. 9. Urbach tail energies for $100 \mathrm{~nm}$ films.

film. However, in this region, $\mathrm{N}$ atoms seem to be replaced by $\mathrm{O}$ atoms, but there may not be enough oxygen present to react with all the Ga. It is not clear what is responsible for the band gap increase at higher $\mathrm{N}_{2}$ fractions.

The correlation between the optical band gap value and the level of $\mathrm{O}$ contamination is most clearly demonstrated as a function of the target bias. The band gap values are very high at low target biases, reaching more than $4.00 \mathrm{eV}$ at $-400 \mathrm{~V}$, but are essentially constant at around $3.03 \mathrm{eV}$ for $-600 \mathrm{~V}$ and above.

\section{Urbach tail energy}

Films which are thick enough for color in transmission to be determined by the absorption of the films rather than by interference are yellowish, except where there is a significant $\mathrm{O}$ contamination. This absorption is visible below the band edge as band tailing into the blue part of the spectrum.

The Urbach tail energy $E_{0}$, which is often used to quantify the band tailing and thus the disorder in the material, is plotted in Fig. 9. As a function of the substrate electrode temperature, the value varies around $150 \mathrm{meV}$ up to $300{ }^{\circ} \mathrm{C}$, possibly decreasing slightly, before increasing rapidly to $470 \mathrm{meV}$ at $375{ }^{\circ} \mathrm{C}$ and to $840 \mathrm{meV}$ at $450{ }^{\circ} \mathrm{C}$. Slack et $a l .{ }^{36}$ have suggested that the Urbach tail could be caused by $\mathrm{O}$ impurities. Figure 7(a) shows how the spectral features of films deposited at higher temperatures and $\mathrm{O}$ content tend to be smeared out.

At low $\mathrm{N}_{2}$ flow rates, the values are large and are likely to be a result of excess $\mathrm{Ga}$, giving rise to significant absorption right into the band gap. There appears to be a shallow minimum at around $40 \% \mathrm{~N}_{2}$, after which the values increase again at higher $\mathrm{N}_{2}$ flow rates. The increase may be related to the decrease in $\mathrm{Ga}$ and to the increase in O. A plot of $E_{0}$ versus the negative target bias voltage also shows a minimum in the range of -600 to $-800 \mathrm{~V}$. Above $-1400 \mathrm{~V}$, the values decrease again. The large values at low target biases may once again be related to the smearing of the band edge by $\mathrm{O}$ contamination. However, the minimum may reflect an improved crystallization due to the low target bias, but without the gross $\mathrm{O}$ contamination of the very low biases.
In regions with more than 5\% O contamination, the band gap exhibits similar trends to those of the Urbach tail energy. The only exception to this is at low $\mathrm{N}_{2}$ flow rates where the films are $\mathrm{Ga}$ rich and the increased oxygenation is only as a response to the decrease in the availability of nitrogen. Because of the way in which the band gaps are inferred from the optical absorption curves, a decrease in the Urbach tail energy should be accompanied by an increase in the band gap because a reduction in tail states should sharpen the band edge. Thus, large values of $E_{0}$ can mostly be ascribed to an excess of oxygen rather than to any real trend in terms of improvement in the crystal structure. The minima in the plots of $E_{0}$ as functions of the $\mathrm{N}_{2}$ flow rate and target bias voltage coincide with the standard deposition conditions. This may indicate that these conditions are close to optimal for the given setup.

\section{Refractive index}

The trends in the refractive indices are essentially opposite to those of the optical band gaps. This is expected because of the Kramers-Kronig relationship between the wavelength dependence of the real and imaginary parts of the refractive index, $n$ and $k$. Films having a large $\mathrm{O}$ content show very low values of refractive index, and the measurement seems to be a fairly sensitive indicator of this. The refractive index of the disordered $\beta-\mathrm{Ga}_{2} \mathrm{O}_{3}$ is 1.89 at $632.8 \mathrm{~nm} .{ }^{32}$ Under standard deposition conditions, the refractive index of the GaN is 2.46 , just short of the highest reliable value of 2.47 at $75^{\circ} \mathrm{C}$. The lowest values were obtained at $450{ }^{\circ} \mathrm{C}(2.03), 90 \% \mathrm{~N}_{2}(2.23)$, and $-400 \mathrm{~V}(1.73-$ 2.04). For the severely oxygenated samples deposited without the quartz shield, refractive index values were in the range $1.91-2.03$ for $30 \%-70 \% \mathrm{~N}_{2}$ and only reached 2.2 at a target bias of $-1400 \mathrm{~V}$.

\section{CONCLUSIONS}

The deposition rates of $\mathrm{GaN}$ films formed by reactive sputtering vary over a wide range, from 0.47 to $25 \mathrm{~nm} / \mathrm{min}$, depending on the deposition conditions. As a function of temperature, pressure, $\mathrm{N}_{2}$ fraction, and target bias, the deposition rates are considered to be controlled, respectively, by thermally activated desorption from the substrate, changes in the mean free path and concentration of gas particles, differences between the sputter yields of $\mathrm{Ga}$ and $\mathrm{GaN}$ in $\mathrm{Ar}$ and $\mathrm{N}_{2}$, and changes in the ion current and sputter yields.

The films are polycrystalline and generally columnar, with the grain size increasing with film thickness. The most crystalline films were grown at midrange temperatures, low $\mathrm{N}_{2}$ concentrations, and low target biases, and the most disordered at low pressures. The latter two cases suggest that decreasing the energy of particles incident on the film during deposition results in a more ordered film. The biaxial stress is compressive and shows an increasing trend with the $\mathrm{N}_{2}$ concentration and target bias.

The stoichiometry, the oxygen contamination in particular, has a major effect on the optical properties of the films, masking any effect of the degree of the structural disorder. Oxygen contamination tends to smear out the band edges and 
shift the band gap values to higher energies. This increases the Urbach tail energies and decreases the refractive index values. Except as a function of $\mathrm{N}_{2}$ in the deposition atmosphere, the $\mathrm{N} / \mathrm{Ga}$ ratio is more or less constant. The absolute oxygen incorporation rate changes very little, but it is the relative film deposition rate which determines the final oxygen concentration. At low $\mathrm{N}_{2}$ concentrations, Ga getters oxygen from the deposition atmosphere in the absence of sufficient atomic nitrogen. The excess Ga makes the films opaque to the naked eye, and this is reflected as a decrease in the band gaps and an increase in the Urbach tail energy.

\section{ACKNOWLEDGMENTS}

The authors would like to thank S. Henley for the SEM, C. Giusca for the AFM, and V. Stolojan for the TEM.

${ }^{1}$ Properties, Processing and Applications of Gallium Nitride and Related Semiconductors, edited by J. H. Edgar, S. Strite, I. Akasaki, H. Amano, and C. Wetzel, EMIS Data Reviews Series Vol. 23 (INSPEC, London, 1999).

${ }^{2}$ J. Ross, M. Rubin, and T. K. Gustafson, J. Mater. Res. 8, 2613 (1993).

${ }^{3}$ Q. X. Guo, A. Okada, H. Kidera, T. Tanaka, M. Nishio, and H. Ogawa, J. Cryst. Growth 237-239, 1079 (2002).

${ }^{4}$ H. J. Hovel and J. J. Cuomo, Appl. Phys. Lett. 20, 71 (1972).

${ }^{5}$ T. Hariu, T. Usuba, H. Adachi, and Y. Shibata, Appl. Phys. Lett. 32, 252 (1978).

${ }^{6}$ E. Lakshmi, B. Mathur, A. B. Bhattacharya, and V. P. Bhargava, Thin Solid Films 74, 77 (1980).

${ }^{7}$ S. Zembutsu and M. Kobayashi, Thin Solid Films 129, 289 (1985).

${ }^{8}$ S. Nonomura, S. Kobayashi, T. Gotoh, S. Hirata, T. Ohmori, T. Itoh, S. Nitta, and K. Morigaki, J. Non-Cryst. Solids 198-200, 174 (1996).

${ }^{9}$ V. Bondar, I. Kucharsky, B. Simkiv, L. Akselrud, V. Davydov, Y. Dubov, and S. Popovich, Phys. Status Solidi A 176, 329 (1999).

${ }^{10}$ W. T. Young, S. R. P. Silva, M. Benyoucef, M. Kuball, J. V. Anguita, J. M. Shannon, K. P. Homewood, and B. J. Sealy, Phys. Status Solidi A 176, 319 (1999).

${ }^{11}$ T. Miyazaki, T. Fujimaki, and S. Adachi, J. Appl. Phys. 89, 8316 (2001).

${ }^{12}$ S. Yagi, S. Suzuki, and T. Iwanaga, Jpn. J. Appl. Phys., Part 2 40, L1349 (2001).
${ }^{13}$ S. Yagi, Appl. Phys. Lett. 76, 345 (2000).

${ }^{14} \mathrm{~K}$. Wasa and S. Hayakawa, Handbook of Sputter Deposition Technology: Principles, Technology and Applications (Noyes, Park Ridge, NJ, 1992).

${ }^{15}$ J. F. Richardson and J. H. Harker, Coulson \& Richardson's Chemical Engineering, 5th ed (Butterworth Heinemann, Washington, D.C., 2002), Vol. 2.

${ }^{16}$ K. L. Chopra, Thin Film Phenomena (McGraw-Hill, New York, 1969).

${ }^{17}$ S. Guha, N. A. Bojarczuk, and D. W. Kisker, Appl. Phys. Lett. 69, 2879 (1996).

${ }^{18}$ C. Adelmann, J. Brault, G. Mula, B. Daudin, L. Lymperakis, and J. Neugebauer, Phys. Rev. B 67, 165419 (2003).

${ }^{19}$ CRC Handbook of Chemistry and Physics, 85 th ed., edited by D. R. Lide (CRC, Cleveland, OH, 2005).

${ }^{20}$ N. Grandjean, J. Massies, F. Semond, S. Y. Karpov, and R. A. Talalaev, Appl. Phys. Lett. 74, 1854 (1999).

${ }^{21}$ J.-C. Lin and C. Lee, J. Electrochem. Soc. 147, 713 (2000).

${ }^{22}$ N. Kumar, K. Pourrezaei, M. Fissel, T. Begley, B. Lee, and E. C. Douglas, J. Vac. Sci. Technol. A 5, 1778 (1987).

${ }^{23}$ J. H. Huang and J. S. Chen, Thin Solid Films 382, 139 (2001).

${ }^{24}$ G. Bertrand, C. Savall, and C. Meunier, Surf. Coat. Technol. 96, 323 (1997).

${ }^{25}$ J. Ross and M. Rubin, Mater. Lett. 12, 215 (1991).

${ }^{26}$ J. Heller, Thin Solid Films 17, 163 (1973).

${ }^{27}$ J. Hrbek, Thin Solid Films 42, 185 (1977).

${ }^{28}$ L. T. Lamont and F. T. Turner, J. Vac. Sci. Technol. 11, 47 (1974).

${ }^{29}$ K. Abe et al., J. Non-Cryst. Solids 227-230, 1096 (1998).

${ }^{30}$ W. T. Young, S. R. P. Silva, J. V. Anguita, J. M. Shannon, K. P. Homewood, and B. J. Sealy, Diamond Relat. Mater. 9, 456 (2000).

${ }^{31}$ V. Prajzler, I. Hüttel, J. Špirková, V. Machovič, J. Schröfel, V. Peřina, and J. Hamáček, Proceedings of Thin Films 2004: The Second International Conference on Technological Advances of Thin Films and Surface Coatings, Singapore, 13-17 July 2004 [CD ROM].

${ }^{32}$ M. Rebien, W. Henrion, M. Hong, J. P. Mannaerts, and M. Fleischer, Appl. Phys. Lett. 81, 250 (2002).

${ }^{33}$ N. Ueda, H. Hosono, R. Waseda, and H. Kawazoe, Appl. Phys. Lett. 70, 3561 (1997).

${ }^{34}$ M. Orita, H. Ohta, M. Hirano, and H. Hosono, Appl. Phys. Lett. 77, 4166 (2000).

${ }^{35}$ K. S. A. Butcher, Afifuddin, P. P. T. Chen, and T. L. Tansley, Phys. Status Solidi C 0, 156 (2002).

${ }^{36}$ G. A. Slack, L. J. Schowalter, S. Morelli, and J. A. Freitas, J. Cryst. Growth 246, 287 (2002). 